\title{
Young Children's Mobile Device Use in Public Places: Immersion, Distraction, and Co-Use
}

\author{
Diana Floegel ${ }^{1}$, Nelly Elias ${ }^{2}$, Dafna Lemish ${ }^{1}$ \\ ${ }^{1}$ School of Communication and Information, Rutgers University, New Brunswick, NJ \\ ${ }^{2}$ Department of Communication Studies, Ben-Gurion University of the Negev, Beer-Sheva, Israel \\ Correspondence: Prof. Nelly Elias, Department of Communication Studies, Ben-Gurion University of the Negev, Beer- \\ Sheva, 84105, Israel.
}

Received: April 10, 2021

doi:10.11114/smc.v9i1.5236

\author{
Accepted: May 4, 2021 \\ Online Published: May 9, 2021 \\ URL: https://doi.org/10.11114/smc.v9i1.5236
}

\begin{abstract}
Though prior research has examined how parents use mobile devices in public, we know less about children's use of mobile devices outside the home. The present study therefore explores how children use mobile devices in public places they visit with their parents in order to conceptualize how device use affects children's interactions with their parents and environments. We used naturalistic non-participant observational methods in three locations in the US: eateries, laundromats, and airports. We observed 77 families with at least one parent and one child estimated to be between 2-6 years old. The observers wrote detailed field notes that we analyzed qualitatively using thematic analysis. We found that children used mobile devices in $31 \%$ of the observed families. We categorized children's behaviors under three themes: immersion, distraction, and co-use. Children were highly engaged with their parents and environment during co-use. However, when children asked for a device or were provided with a device that they used on their own, they were less engaged with parents and environments. Engagement levels between children and parents therefore corresponded with the circumstances of children's device use and whether they used devices with their parents or in isolation from them. The themes we develop here may be applied to future qualitative and quantitative studies of children's mobile device use in public and at home.
\end{abstract}

Keywords: children, mobile phone, public place, parent-child communication

\section{Introduction}

Throughout early childhood, children spend significant time with their parents outside the home, participating in activities such as running errands, playing at the playground, having a family meal in various eateries, or shopping at the supermarket. Despite their routine and taken for granted nature, these outings play an important role in children's socialization and development: They provide children with stimuli that enhance general knowledge, foster encounters with new people outside their social networks, and challenge them with experiences in which they may acquire significant social skills like patience, restraint, and courtesy. These occasions are equally important for strengthening parents' and children's relationships.

However, children have become increasingly engaged with mobile devices such as smartphones and tablets both at home and in public. While researchers have examined children's media use in the home, fewer studies exist that investigate children's device-related behaviors in public. Therefore, we seek to explore whether and how young children use mobile media in public places and how devices impact their interactions with parents and their broader surroundings. More specifically, we wish to determine:

1. How young children interact with their environment and respond to external stimuli while using mobile media;

2. How mobile media are integrated into parent-child communication; and

3. What challenges mobile media pose to children's learning and socialization that take place in public spaces. 


\section{Literature Review}

\subsection{The Role of Interactive Mobile Media in Children's Lives}

Young children are increasingly exposed to mobile media given the mediatization of childhood, wherein the media and the institutions behind them permeate all aspects and levels of children's personal and social lives (Krotz, 2007; Livingstone, 2014; Paus-Hasebrink, Kulterer, \& Sinner, 2019). This phenomenon became even more prominent as mobile media turned interactive: The introduction of the iPhone in 2007 marked the birth of the Digitods - a new generation of children born with ready access to a vast range of mobile touchscreen media (Holloway, Green, \& Stevenson, 2015). In the United States, for example, recent surveys reported that $97 \%$ of children aged 0-8 live in a home with some type of mobile device, while $48 \%$ of children have their own mobile device (Rideout \& Robb, 2020). The average amount of time children spent with mobile devices each day tripled between 2011 and 2017 (Common Sense Census, 2017). Radesky et al. (2020) found that children ages 3-5 used devices an average of about two hours per day, while Rideout and Robb (2020) reported that prior to the COVID-19 pandemic, children under the age of 8 used screen media for about two and a half hours a day. Mobile media accounted for a significant portion of such screen time. Children used devices including tablets, smartphones, and iPod Touches (or similar to), in descending order of frequency, watch online videos, play games, watch TV/movies, use apps, and read books (Rideout \& Robb, 2020).

Recent empirical evidence indicated that toddlers and young children are drawn to touchscreen devices because devices' facile operation characteristics enable them to engage with their favorite apps and websites without adult intervention, affording them a personal sense of agency, achievement, and control over technology (Holloway, Green \& Love, 2014; Neumann, 2014). Thus, children's ability to gain from mobile media has attracted important scholarly attention (Barr, 2010; Chang et al., 2018). Children under the age of two gradually develop touchscreen skills and familiarity with mobile devices' basic functions. Once they reach ages 3-5, children tend to prefer games, drawing/painting applications, and music listening - preferences that also remain dominant among 5-8-year-olds (Goh, Bay, \& Chen, 2015; KostyrkaAllchorne, Cooper, \& Simpson, 2017; Ofcom, 2014; Rideout, 2013).

To date, research has yielded mixed results regarding the possible effects of young children's mobile media use. On the one hand, results of interventions with children ages 2-3 indicated that educational apps contributed to their acquisition of pre-literacy skills (Troseth, Russo, \& Strouse, 2016). Similarly, frequent use of apps with tools for drawing, painting, and building new shapes enhanced creativity and fine motor skills among children ages 4-5, while educational apps enhanced 4-year-olds' vocabulary acquisition (Dore et al., 2019). These apps provided positive feedback when children successfully completed tasks, thereby empowering children's learning processes and increasing their sense of competence, independent accomplishment, and self-worth (Muis, Ranellucci, Trevors, \& Duffy, 2015; Neumann, 2014).

On the other hand, recent studies raised concerns regarding digital devices' potential negative effects on young children's development. One primary issue is parents' tendency to use smartphones and tablets as "pacifiers" or "playpens"- parents hand children mobile devices to occupy them, calm them down, reward, or discipline them (Barlev \& Elias, 2020; Elias \& Lemish, 2021; Chen, Chen, Wen, \& Snow, 2020; Holloway, Green, \& Love, 2014; Kabali et al., 2015). Scholars argue that habituating children to calming themselves with mobile devices may disrupt their development of internal selfregulation mechanisms. Furthermore, intense engagement with interactive apps might displace children's language- and play-based interactions with parents, siblings, or peers (Radesky, Schumacher, \& Zuckerman, 2015). Similarly, parents' own use of mobile media may keep them from interacting with their children in healthy and beneficial ways (Elias, Lemish, Dalyot, \& Floegel, 2020; Steiner-Adair \& Barker, 2013; Turkle, 2011). Accordingly, phenomena such as parental screen distraction (Blackman, 2015) and technoference (i.e., technology's interference in parent-child interactions) (McDaniel \& Radesky, 2018) were found to affect parent-child interactions, often in negative ways.

Research on children's mobile device use is typically situated within the home environment. A gap exists in our understanding of how children use mobile media away from home as well as how device use affects children's behaviors in public. For example, on the positive side, parents may use mobile devices for educational purposes or shared entertainment while waiting with their children in various locations. On the negative side, device use may adversely affect parent-child communication, thereby hampering children's psychological development and public socialization.

A handful of recent studies focuses on parents' phone use while they spend time with their children in various public places, such as playgrounds and eateries. Landmark studies in this domain found that parents frequently use devices during outings; while using a device, parents tend to ignore their children's attempts to interact with them (Elias, Lemish, Dalyot, \& Floegel, 2020; Hiniker et al., 2015; Radesky et al., 2014). Radesky et al.'s (2014) qualitative study of families in fast-food restaurants in the US found that, in contrast to their parents, children rarely used devices in public. These data, however, were collected in 2013. Given the rise in children's mobile media use, it is worth revisiting their device-related behaviors in public settings. 


\subsection{Media Use in Public Places}

Consumption of media outside of the home is not a new phenomenon. Habermas (1992), for example, discussed the implications of collective newspaper reading in French cafés during the $19^{\text {th }}$ century for the cultivation of democratic processes. However, it was only with the advent of electronic media and their growing presence in public that researchers began studying the social order that developed around public media consumption. Lemish $(1982,1985)$ examined television viewing behavior in various settings, including department stores, pubs, waiting areas, and student lounges. She found that common viewing created social relationships among participants (e.g., strangers conversed about the program viewed; people adapted their viewing behavior to suit the characteristics of the space). Viewers were also considerate of each other, displaying cognizance of one another's needs. Lemish concluded that viewing television in public places is not an individualistic or passive activity, but is characterized by collaboration and reciprocity. The sociality surrounding television viewing in public spaces was also the focus of a cross-cultural study conducted in Germany and the US (Krotz \& Eastman, 1999). Here as well, the researchers discerned social codes of behavior during joint viewings, such as the expectation to refrain from disturbing others during their engagement with the medium.

Studies on the use of laptops in public places demonstrated a similar tendency, as some people formed relationships with each other while working in the same place. Although individual media activity was projected to disconnect people from each other, their shared interest in technologies connected them and provided opportunities for spontaneous conversations (Hampton, Livio, \& Sessions, 2010). Further, research on the use of media in public space started to expand as media became increasingly mobile (Cohen, Lemish, \& Schejter, 2008; Ito, Okabe, \& Anderson, 2007; Katz \& Aakhus, 2002). Some studies suggested that intense use of mobile phones in public reinforced individual social ties at the expense of emerging new connections among people in a shared space (Habuchi, 2005; Humphreys, 2005; Kobayashi \& Boase, 2014). In this respect, Habuchi (2005) offered the Tele-Cocooning Hypothesis, according to which users do not have to explore new social connections in their immediate physical space because they are in contact with the people they need, irrespective of location. Likewise, Bull (2004) called this phenomenon a bubble, in an attempt to describe the sense of disconnection from physical space that mobile phones can provide.

Furthermore, the rapid adoption of smartphones - which offer extensive Internet surfing, sophisticated gaming, information and news applications, and access to social media - intensifies mobile devices' potential impact on social life. Literature suggests that constant Internet access reduces the need for personal interactions in the immediate physical environment (Ito, Okabe, \& Anderson, 2009). In this sense, smartphones blur the distinction between a person's physical and virtual spaces, creating a personal mobile territory independent of geographic location wherein a person may shift seamlessly among various social spaces and orders (Chayko, 2021; De Souza e Silva \& Firth, 2012; Hatuka \& Toch, 2014). Phubbing - a portmanteau of the words "phone" and "snubbing" (Roberts \& David, 2016) — describes a closely related phenomenon wherein a person becomes engrossed in their smartphone during a face-to-face interaction. When someone is "phubbed," they may feel ignored or excluded (David \& Roberts, 2017). Children acutely feel the effects of their parents' phubbing behavior, which Xie et al. (2019) describe as "[parents'] undesirable mobile phone usage when they are interacting with children and adolescents" (p. 2). Phubbing disrupts parent-child relationships and may correspond with children's and adolescents' disruptive behaviors (ibid, 2019).

On the other hand, studies note that mobile devices may add to, rather than detract from, social connections in public spaces (Campbell, 2019). From this perspective, phones are not exclusively "cocoons" or harbingers of insularity. Instead, they have the potential to build bonds and bridges (Wilken, 2011) that potentially strengthen social connections in both virtual (Kobayashi et al., 2015) and face-to-face (Chayko, 2021) contexts. Such connections include parent-child bonds when smartphones offer opportunities for co-use and other forms of digital and physical interaction (Schrock, 2016). Smartphones may also enhance people's interactions with physical spaces through, for example, visual, informational, and gamified digital contents that map onto various geolocations (Hjorth \& Pink, 2014).

Given the importance of public space in children's development and socialization to society's norms and patterns of behavior, it is crucial to examine children's media use in public and identify various media use patterns among parents and children on the continuum between a digital "bubble" and shared media use. Accordingly, in this study we examine children's mobile-phone-related behaviors in public places. By doing so, we expand on prior scholarship that focused mainly on adult mobile phone-related behaviors in public. Further, we chose to examine children's behaviors in a variety of locations characterized by different behavioral goals, expectations, and constraints: eateries, airports, and laundromats. In each location, we contextualized our phenomenon of interest vis-a-vis child-device, child-parent, and childenvironment interactions. 


\section{Methods}

\subsection{Study Design}

Forty-two observations of 77 families were conducted from May-November of 2018 in the US. Observations followed guidelines for naturalistic unobtrusive observation of public places that are utilized in the social sciences (Lemish, 1985). An inductive approach to qualitative data analysis guided the development of behavioral categories. The study was approved by Rutgers University IRB.

\subsection{Observation Sites and Participants}

Researchers observed parents and children in three types of locations that involved waiting periods: eateries, airports, and laundromats. Thirty of the 42 observations took place in four different eateries in central New Jersey: a café where customers order at a counter and wait for their food at self-selected tables (10 observations, 18 families), a mall food court (10 observations, 34 families), and two sit-down eateries where customers are seated and waited on by staff (10 observations, 13 families). Five observations took place in a laundromat in central New Jersey where four families were observed, and seven observations took place within five different airports respectively located in New Jersey, New York, New Mexico, Illinois, and California, where eight families were observed (see Table 1). For the laundromat and eateries, neighborhoods in central New Jersey were selected based on demographic factors including average household income. Given restrictions on airport access, airports were selected based on where the researchers traveled and could access preboarding gates. This convenience sampling strategy is not meant to represent the general population, but it allowed for the observation of diverse families and provided insights into the phenomena of interest. Each observation period lasted for approximately two hours.

Table 1. Family characteristics

\begin{tabular}{ll}
\hline & $n(\%)$ \\
\hline Total number of families & 77 \\
Location & \\
Sit down & $13(17 \%)$ \\
Café & $18(23 \%)$ \\
Food court & $34(44 \%)$ \\
Airports & $8(10 \%)$ \\
Laundromat & $4(5 \%)$ \\
Number of parents & 111 \\
Mothers & $62(56 \%)$ \\
Fathers & $49(44 \%)$ \\
Number of children & 94 \\
Toddlers & $28(30 \%)$ \\
Preschoolers & $66(70 \%)$ \\
Girls & $48(51 \%)$ \\
Boys & $46(49 \%)$ \\
Children's use of mobile phone per family & \\
Yes & $24(31 \%)$ \\
No & $53(69 \%)$ \\
Parents' use of mobile phone per family & \\
Yes & $60(78 \%)$ \\
No & $17(22 \%)$ \\
\hline
\end{tabular}

Observations were limited to families that included at least one parent and at least one child between the ages of 2-6. Children were classified into two groups: toddlers (ages 2-3) and preschoolers (ages 4-6). Children's ages were estimated based on observable factors including their height, motor skills, speech, whether they wore a diaper, etc. Older children were excluded from this study because their more advanced physical, cognitive, and emotional development change the character of their interactions with both their parents and mobile devices. 


\subsection{Data Collection and Analysis}

All researchers had training in qualitative ethnographic methods prior to conducting this study, and the research assistants were provided with additional training by the leading investigators, who have extensive backgrounds in childhood studies and qualitative methods. The research assistants piloted each location and method before officially conducting and recording fieldwork. Researchers recorded extensive field notes following a thorough guidebook, including detailed information about each location, the behaviors and interactions they witnessed, and how behaviors and interactions sequentially unfolded (e.g., including timestamps). They analyzed field notes following standard procedures for qualitative thematic analysis, including the inductive development of a coding scheme and the development of a descriptive typology of mobile device use and associated behaviors and interactions. Common techniques in qualitative interpretive research were used to assess the findings' trustworthiness, including peer debriefing (Lincoln \& Guba, 1985) and determination of inter-coder agreement (Zhang \& Wildemuth, 2005). This paper presents a portion of the developed typology that explicitly pertains to children's device use and its relationship to parent-child and child-environment interactions.

\section{Results}

Of the 77 total families observed, 24 families (31\%) demonstrated children's mobile device use (see Table 1) in comparison to 60 families (78\%) who demonstrated parents' device use. Our results for children's use echo the Common Sense Census from 2020, which found that $21 \%$ of children aged 0-8 use mobile devices during restaurant meals, with $27 \%$ of 2-4-year-olds and $23 \%$ of 5-8-year-olds using a device in eateries (Rideout \& Robb, 2020).

We categorize children's use under three prominent and, at times, intersecting behaviors - immersion, distraction, and couse. Results suggest how these behaviors correspond with interactional patterns between parents and children labeled as disengagement, divided engagement, and high engagement with each other. The term "engagement" describes parents' and children's attention towards each other and mobile devices during outings; it builds on prior findings from this study related to parents' device use (Lemish, Elias, \& Floegel, 2020).

\subsection{Immersion}

Immersion was observed in $27 \%$ of families $(n=21)$ and characterizes observational episodes where children were disengaged from their families and environments. In all locations except sit-down eateries, the researchers most often observed children immerse themselves in mobile phone-related activities. This corresponded with their withdrawal from interactions with their parents and general social environment. For example:

A family consisting of a preschool-aged son, toddler-aged son, mother, and father sit down after ordering at the counter. The preschooler takes a mobile phone from his pocket and begins to look at it. He does not interact with any other family members while looking at the screen. When the food arrives, the preschooler begins to eat his personal pizza without looking up from the screen. His mother says something to him and he does not respond. After the toddler finishes eating, he tries to look at the preschooler's phone screen, but the preschooler says "no" and pushes him away without looking up. When the family leaves the café, the preschooler holds the phone and continues to look at it while they exit. He used the phone for the entirety of the family's 30-minute trip to the café (Café, 8/10/18).

Children's disengagement from their families did not differ depending on factors such as their assumed gender, nor did it seem to be affected by family composition (e.g., whether one or multiple parents or siblings were present). However, age corresponded with children's immersion: preschoolers were immersed more often than toddlers, who in general had shorter attention spans when they used a mobile phone.

Children who demonstrated immersion often started to use a device soon after they entered an establishment; they either asked their parents for a phone or they had their own device. Immersed children kept their heads down to look at their phone screen, and they most frequently watched videos on YouTube. Parents' behaviors varied while children were immersed. Some left their children to the device and engaged in conversation with other adults or took out a device of their own. These parents seemed unbothered by their children's behaviors. Others, however, tried and failed to interact with their children. When parents attempted to capture their child's attention by speaking with them, offering them food and drink, or trying to hug them, the children neither acknowledged nor reciprocated any gesture. The following excerpt from an observation in a sit-down restaurant exemplifies these circumstances:

A family comprised of a mother, father, toddler-aged son, toddler-aged daughter, and preschool-aged daughter arrives at the restaurant and the host seats them. The toddler-aged son taps his mother on the shoulder and holds out his hand. She reaches into her bag and hands him a smartphone. He appears to play a game on the phone and he stops interacting with anyone else at the table. After a few minutes, his mother asks him what he is doing with the phone, and he does not respond. The server brings the family's drinks and the toddler does not look up. His 
mother offers him a drink, but he ignores her and continues to play with the phone in silence. She leans over and tries to hug him; he does not react. When the food comes, he eats with one hand and holds the phone with another. He used the phone for 60 out of the 70 minutes the family spent in the restaurant (Sit-down restaurant, 5/29/18).

In addition to their parents, children ignored their surrounding environments when immersed in a phone. In eateries, they did not react when people brought food and drink to the table, and they continued to watch content while eating. They did not pay attention to other people's activities at laundromats or announcements over loudspeakers at airports. In general, immersed children did not look at or otherwise engage with their surroundings while they had their phone in hand. Immersed children's behaviors are therefore classified as disengaged from their parents and environments altogether.

The highest proportion of children - about half - displayed immersion and corresponding disengagement in airports, the laundromat, and at the café. These findings correspond with the amount of uninterrupted waiting time in each of these three locations. At the airport, laundromat, and café, families spent the longest amount of time waiting for something to happen - boarding a plane, finishing laundry, and obtaining food - as opposed to the other locations. For example, children's immersion was observed in only four families at the food court, where parents and children did not have to wait for their food to be delivered and where visits were relatively short. Likewise, immersion was identified in three families at sit-down eateries, where periods of waiting were broken up by interactions with servers and deliveries of drinks and multiple courses of food. Locations and their corresponding wait times seem more important than families' make-up or attributes. However, when immersion was observed at the food court and sit-down eateries, similar patterns of full disengagement between children and parents were found.

\subsection{Distraction}

Distraction describes situations where parents provided children with a mobile device in order to occupy them in a given setting. Distraction was observed in $13 \%$ of families $(\mathrm{n}=10)$. Often, this behavior corresponded with parents' apparent desire to disengage with their children and direct their attention towards other adults or their own mobile devices. Alternatively, parents provided children with a phone when they were acting restless (e.g., trying to leave the table at a restaurant or making loud noises in the airport). When parents provided children with a device in order to distract them, children either became immersed in the phone for some time, or they became bored or disinterested with it, leading to divided engagement with their parents. Sometimes the distraction lasted very briefly; this was especially true among toddler-aged children. For example:

A father sits down with his toddler-aged son while the son's mother gets them food. The son starts to squirm, perhaps looking for his mother. The father tries to hold his son in the chair. When the son continues to move around, his father takes out a mobile phone and holds it in front of his son's face. The son stops squirming and looks down at the phone screen for approximately five minutes. Then he loses interest in the phone screen, climbs into his father's lap, and looks around the food court until his mother arrives with their meal (Food court, 6/23/18).

In this episode, the son was not distracted by his father's phone for long. At other times, distractions were effective over a longer time. Preschool-aged children were more susceptible to being distracted by a mobile phone, as in the following observation:

A father and his preschool-aged son wait for their clothes to dry at the laundromat. When their clothes are dry, the father starts to fold them, and the son sits down and starts to kick his legs and yell "Yes!" and "No!". The father gives the son his phone and the son falls silent and still. He looks at the screen while his father folds clothes. The son is mesmerized for approximately 30 minutes until the family leaves the laundromat. The son continues to look down at his father's device while they exit (Laundromat, 6/23/18).

Though parents used other "tools" such as coloring and toys to occupy their children, mobile phones were the most frequently offered distractions. As with immersion, distraction was most often observed in airports and laundromats, where parents and children spent longer amounts of time with fewer interruptions.

There are key differences between distraction and immersion. Children who were immersed in their phones often initiated their own use, while with distraction, parents provided the phones. Immersed children most often watched content like videos, while distracted children demonstrated a wider range of digital activities, such as playing games, taking pictures, or watching content. Finally, immersed children were fully absorbed in their phones, while distracted children were less absorbed. They tried to recapture their parents' attention and they looked away from the phones to observe other elements of their environments, like noises and people. However, distraction could transition into immersion, especially among preschoolers who became immersed after their parents provided a phone to distract them.

\subsection{Co-use}

Co-use describes instances in which children used a device with their parents, as observed in $17 \%$ of families ( $\mathrm{n}=13$ ). Parents and children watched videos, played games, looked for information, and talked on the phone together. Most of 
these families included dyads consisting of one child and one parent who interacted with each other while using a device. Unlike interactions related to immersion and distraction, these were high-engagement interactions. Most often, parents used a phone and invited their children to share the device with them. Children cooperated willingly and seemed excited about the opportunity to join their parents in watching a video or playing a game. For example:

A preschool-aged boy and his father both have a mobile device. Before the father goes over to the washing machines, he and his son start to play the same interactive game on their respective devices. The father goes to the machines and the son remains seated, but they continue to play their game from a distance. They laugh, point at each other, and converse. When the father makes a certain move in the game, the son stands up and playfully punches his father's arm, then goes back to his seat to keep playing (Laundromat, 6/23/18).

When parents invited their children to use a device, they looked keen to entertain their children while they tended to laundry or waited for food or an airplane. Furthermore, co-use corresponded with positive interactions between parents and children wherein they were physically affectionate and conversed about what they were doing. The following exemplifies these behaviors:

A mother and her preschool-aged daughter sit next to each other and watch a device together. For the duration of their time at the restaurant, they watch the screen while waiting for their food and eating. The mother often has her arm around her daughter, and they giggle and occasionally chat about the content they watch. Both seem happy and relaxed (Sit-down restaurant, 8/26/18).

During instances of co-use, children paid attention to their parents and their device (e.g., the conversation centered the content on the device), while they were less attentive to other people or events in their vicinities. Parents, on the other hand, split their attention between the device, their child, and their environment. For example, they also interacted with serving staff at a restaurant, kept tabs on their laundry, or listened for announcements about flights.

More co-use was observed in sit-down restaurants than immersion or distraction. This could be because waiting periods there were longer than in the other eateries, and the outings were family occasions with the expectation for "quality time." Moreover, as with "distraction," mobile devices were not the only cause for co-use. Parents and children also colored and played with toys together. These activities constituted high engagement and seemingly fun interactions. However, mobile phones were the most commonly observed tool for shared activities. Additionally, one sit-down restaurant provided diners with tablets at each table. Three of four families observed at this location used the tablet together, most often to play a game. This led to enthusiastic play between parents and children while they waited for food.

\section{Discussion and Conclusion}

The present study examined young children's interactions with their parents and broader environment while using mobile media in various public places and the challenges mobile media pose to children's learning and socialization that take place in these spaces. Naturalistic non-participant observations of parents and children in three types of public placeseateries, airports, and laundromats - demonstrate that toddlers and preschoolers frequently use mobile devices in these settings. This is a major finding given that studies of family mobile device use either center children's behaviors in the home or parents' behaviors in public. Little scholarship to date examines children's behaviors with devices in public, and emerging scholarship in this domain uses quantitative methods that are contextualized by the qualitative results presented here (e.g., Radesky et al., 2020).

This study's analysis of observational field notes finds that when children use mobile devices, they may be fully immersed in a device, distracted at least in part by a device, or co-using a device with their parents. Children's various device-related behaviors correspond with their relative engagement with their parents and their wider environments. Most often, children who are immersed in a device disengage from their parents and social setting while children who are distracted by a device are partially engaged with their parents and environments - behaviors that align with documented phenomena that have previously been attributed to adults, like tele-cocooning (Habuchi, 2005) and phubbing (Xie et al., 2019). On the other hand, children who co-use a device are highly engaged with their parents and less aware of their surroundings. Findings related to co-use support research which argues that mobile phones do not deterministically isolate people from their non-virtual lives; phones can encourage parent-child bonding activities (Schronck, 2016).

Behaviors' correspondence with engagement levels may have to do with whose needs or desires are met by children's device use, as well as children's activities when they use a device. With immersion, children largely satisfy their own need to entertain themselves with a device, and they are most often absorbed by video content that they select. With distraction, parents provide children with a device so they may have a conversation with other adults, use their own device, or ostensibly have some peace in a public setting. On these occasions, parents may encourage their children to play a game or engage in another digital activity that is not of the children's choosing. Here, we emphasize that under certain circumstances, parents use mobile phones as "pacifiers" (Barlev \& Elias, 2020) or "playpens" (Elias \& Lemish, 2021) so 
that children do not disturb their parents. Co-use, on the other hand, relates to circumstances where parents entertain their children by using a device with them. Children are happy to receive invitations to co-use devices with their parents, and they engage with their parents in relation to whatever activity they do together.

Results suggest that location can influence children's behaviors and interactions with mobile devices, parents, and broader social surroundings. Locations with longer waiting periods, like laundromats and airports, correspond with higher rates of immersion and distraction. Locations with shorter periods between activities that are associated with family time, like sit-down restaurants, correspond with higher rates of co-use. Location was more significant than demographic factors in this study. However, children's age corresponded with their immersion in a device. Preschoolers became immersed more easily than toddlers, which may have to do with their social and cognitive development, their socialization to the affordances of mobile devices, or the higher likelihood that they possess their own device, especially among wealthier families (Goh, Bay, \& Chen, 2015; Rideout \& Robb, 2020).

Though mobile devices were the most common mediums parents and children used in public, they were not the only mediums observed in this study. Children also colored or played with toys, both of which occupied them across settings. These activities served similar functions to mobile devices. This leads to an important insight: while mobile devices may be framed as particularly unique technologies, they function as a modern iteration of mobile entertainment that children engage with while in public with their parents. All of these activities have the potential to be isolating, distracting, or bonding facilitators. However, our findings do demonstrate that children's use of mobile phones in public often corresponds with withdrawal from both their parents and their broader environments.

The results reported here have significant implications for child development. On the one hand, mobile device use relates to children's disengagement from key socializing agents in public places, which may affect children's development of patience, conversational skills, and other important abilities (see Radesky et al., 2015). On the other hand, mobile device use has the potential to enrich child development via educational digital activities and potential bonding with parents from co-use (see Schrock, 2016). Hence, there is likely a balance that can be struck between children's mobile device use in public and their unmediated socialization to physical public spaces.

This study is not without limitations. This is a qualitative case study based on a limited convenience sample of observations and thus does not allow for generalizations. Furthermore, our observations were not distributed evenly between the various locations, especially because it was difficult to observe families in airport boarding areas. The unobtrusive observations did not allow us to follow up with the children and their parents to learn about their own perspectives and interpretations of their behaviors. The insights of this study thus beg for further investigation and testing. One promising direction for future research involves further investigating connections between mobile devices and other mobile forms of entertainment (both digital and non-digital) used by children while they are in public with their parents. Additional methods could foster in-depth comparison between children's device use in the home versus in public, as well as similarities and differences between uses of mobile devices and other media such as television. Accounting for contextual factors and families' perceptions of mobile device use will add insightful nuance to the results we report here. However, the study offers novel contributions related to mobile devices' effects on parent-child interactions in public places and children's socialization to public space in general. Our findings can be used in future research that generates needed discussion around technology's role in early childhood and families' everyday lives and interactions.

\section{Acknowledgments}

We would like to thank our research assistant Daniel Delmonaco at Rutgers University for his valuable contribution to this study.

\section{Funding}

This research was funded by the United States-Israel Binational Science Foundation (BSF), Jerusalem, Israel.

\section{References}

Barlev, Y., \& Elias, N. (2020). Digital parenting: Media uses in parenting routines during the first two years of life. Studies in Media and Communication, 8(2), 41-48. https://doi.org/10.11114/smc.v8i2.5050

Barr, R. (2010). Transfer of learning between 2D and 3D sources during infancy: Informing theory and practice. Developmental Review, 30(2), 505-522. https://doi.org/10.1016/j.dr.2010.03.001

Blackman, A. (2015). Screen time for parents and caregivers: Parental screen distraction and parenting perceptions and beliefs (Unpublished doctoral dissertation). Pace University, New York, NY.

Bull, M. (2004). "To each their own bubble": Mobile space of sound in the city. In N. Couldry \& A. McCarthy (Eds.), Media/Space: Place, scale and culture in a media age (pp. 275-293). London, UK: Routledge.

Campbell, S.W. (2019). From frontier to field: Old and new theoretical directions in mobile communication studies. 
Communication Theory, 29(1), 46-65.

Chang, H.Y., Park, E., Yoo, H., won Lee, J., \& Shin, Y. (2018). Electronic media exposure and use among toddlers. Psychiatry Investigation, 15(6), 568-573. https://doi.org/10.30773/pi.2017.11.30.2

Chayko, M. (2021). Superconnected: The internet, digital media, and techno-social life. Los Angeles: Sage.

Chen, C., Chen, S., Wen, P., \& Snow, C.E. (2020). Are screen devices soothing children or soothing parents? Investigating the relationships among children's exposure to different types of screen media, parental efficacy, and home literary practices. Computers in Human Behavior, 112, 106462. https://doi.org/10.1016/j.chb.2020.106462

Cohen, A. A., Lemish, D. \& Schejter, A. M. (2008). The wonder phone in the land of miracles: Mobile telephony in Israel. Cresskill, NJ: The Hampton Press.

Common Sense Media (2017). The common sense census: Media use by kids age zero to eight, 2017. Common Sense Media report. Retrieved from https://www.commonsensemedia.org/research/the-common-sense-census-media-useby-kids-age-zero-to-eight-2017

David, M. E., \& Roberts, J. A. (2017). Phubbed and alone: Phone snubbing, social exclusion, and attachment to social media. Journal of the Association for Consumer Research, 2(2), 155-163. https://doi.org/10.1086/690940

De Souza e Silva, A., \& Firth, J. (2012). Mobile interface in public spaces: Locational privacy control and urban sociability. New York: Routledge. https://doi.org/10.4324/9780203123966

Dore, R. A., Shirilla, M., Hopkins, E., Collins, M., et al. (2019). Education in the app store: Using a mobile game to support U.S. preschoolers' vocabulary learning. Journal of Children and Media, 13(4), 452-471. https://doi.org/10.1080/17482798.2019.1650788

Elias, N., \& Lemish, D. (2021). Parental social uses of the mobile phone in public places: The case of eateries in two national contexts. International Journal of Communication, 15, 2086-2104. https://ijoc.org/index.php/ijoc/article/viewFile/16916/3430

Elias, N., Lemish, D., Dalyot, S., \& Floegel, D. (2020). Where are you? An observational exploration of parental technoference in public places in the US and Israel. Journal of Children and Media. https://doi.org/10.1080/17482798.2020.1815228

Goh, W. W., Bay, S., \& Chen, V. H. H. (2015). Young school children's use of digital devices and parental rules. Telematics and Informatics, 32(4), 787-795. https://doi.org/10.1016/j.tele.2015.04.002

Habermas, J. (1992). The structural transformation of the public sphere: An inquiry into a category of bourgeois society. Cambridge, MA: MIT Press.

Habuchi, I. (2005). Accelerating reflexivity. In M. Ito, D. Okabe \& M. Matsuda (Eds.), Personal, portable, pedestrian: Mobile phones in Japanese life (pp. 165-182). Cambridge, MA: MIT Press.

Hampton, K. N., Livio, O., \& Sessions Goulet, L. (2010). The social life of wireless urban spaces: Internet use, social networks, and the public realm. Journal of Communication, 60(4), 701-722. https://doi.org/10.1111/j.14602466.2010.01510.x

Hatuka, T., \& Toch, E. (2014). The emerge of portable privet-personal territory: Smartphone social conduct and public space. Urban Studies, 53(10), 2192-2208. https://doi.org/10.1177/0042098014524608

Hiniker, A., Sobel, K., Suh, H., Sung, Y. C., Lee, C. P., \& Kientz, J. A. (2015). Texting while parenting: How adults use mobile phones while caring for children at the playground. Proceedings of the 33rd Annual ACM Conference on Human Factors in Computing Systems (pp. 727-736). https://doi.org/10.1145/2702123.2702199

Hjorth, L., \& Pink, S. (2014). New visualities and the digital wayfarer: Reconceptualizing camera phone photography and locative media. Mobile Media \& Communication, 2(1), 40-57. https://doi.org/10.1177/2050157913505257

Holloway, D. J., Green, L., \& Stevenson, K. (2015). Digitods: Toddlers, touch screens and Australian family life. $M / C$ Journal, 18(5). https://doi.org/10.5204/mcj.1024

Holloway, D., Green, L., \& Love, C. (2014). 'It's all about the apps': Parental mediation of preschoolers' digital lives. Media International Australia, Incorporating Culture \& Policy, 153, 148-156. https://doi.org/10.1177/1329878X1415300117

Humphreys, L. (2005). Cellphones in public: social interactions in a wireless era. New Media \& Society, 7(6), 810-833. https://doi.org/10.1177/1461444805058164

Ito, M., Okabe, D., \& Anderson, K. (2009). Portable objects in three global cities: The personalization of urban places. In 
R. Lind \& S. Campbell (Eds.), The reconstruction of space and time through mobile communication practices (pp. 67-87). New Brunswick, NJ: Transaction Books. https://doi.org/10.4324/9781315134499-4

Kabali, H. K., Irigoyen, M. M., Nunez-Davis, R., Budacki, G. J., Mohanty, H. S., Leister, P. K., \& Bonner, L. R. (2015). Exposure and use of mobile media devices by young children. Pediatrics, 136(6), 1044-1050. https://doi.org/10.1542/peds.2015-2151

Katz, J. E. \& Aakhus, M. (2002). Perpetual contact: Mobile communication, private talk, public performance. Cambridge, UK: Cambridge University Press. https://doi.org/10.1017/CBO9780511489471

Kobayashi, T., \& Boase, J. (2014). Tele-Cocooning: Mobile texting and social scope. Journal of Computer-Mediated Communication, 19, 681-694. https://doi.org/10.1111/jec4.12064

Kostyrka-Allchorne, K., Cooper, N. R., \& Simpson, A. (2017). Touchscreen generation: Children's current media use, parental supervision methods and attitudes towards contemporary media. ACTA Paediatrica: Nurturing the Child, 106(4), 654-662. https://doi.org/10.1111/apa.13707

Krotz, F. (2007). The meta-process of "mediatization" as a conceptual frame. Global Media and Communication, 3(3), 256-260. https://doi.org/10.1177/17427665070030030103

Krotz, F., \& Eastman S. T. (1999). Orientations toward television outside the home. Journal of Communication, 49(1), 5 27. https://doi.org/10.1111/j.1460-2466.1999.tb02779.x

Lemish, D. (1982). The rules of viewing television in public places. Journal of Broadcasting, 26(4), 757-781. https://doi.org/10.1080/08838158209364046

Lemish, D. (1985). Soap opera viewing in college: A naturalistic inquiry. Journal of Broadcasting \& Electronic Media, 29(3), 275-293. https://doi.org/10.1080/08838158509386585

Lemish, D., Elias, N., \& Floegel, D. (2020). "Look at me!" Parental use of mobile phones in the playground. Mobile Media and Communication, 8(2), 170-187. https://doi.org/10.1177/2050157919846916

Lincoln, Y. S., \& Guba, E. G. (1985). Naturalistic Inquiry. Newbury Park, CA: SAGE. https://doi.org/10.1016/01471767(85)90062-8

Livingstone, S. (2014). The mediatization of childhood and education: Reflections on The Class. In L. Kramp, N. Carpentier, A. Hepp, I. Tomanic-Trivundza, H. Nieminen, R. Kunelius, T. Olsson, E. Sudin, \& R. Kilborn (Eds.), Media practice and everyday agency in Europe. Edition Lumiére. http://eprints.lse.ac.uk/62120/

McDaniel, B. T., \& Radesky, J. S. (2018). Technoference: Parent distraction with technology and associations with child behavior problems. Child Development, 89(1), 100-109. https://doi.org/10.1111/cdev.12822

Muis, K. R., Ranellucci, J., Trevors, G., \& Duffy, M. C. (2015). The effects of technology-mediated immediate feedback on kindergarten students' attitudes, emotions, engagement and learning outcomes during literacy skills development. Learning and Instruction, 38, 1-13. https://doi.org/10.1016/j.learninstruc.2015.02.001

Neumann, M. M. (2014). An examination of touch screen tablets and emergent literacy in Australian pre-school children. Australian Journal of Education, 58(2), 109-122. https://doi.org/10.1177/0004944114523368

Ofcom, (2014). Children and parents: Media use and attitudes report. Ofcom, London: Office of Communications. Retrieved from http://stakeholders.ofcom.org.uk/binaries/research/media-literacy/media-use-attitudes14/Childrens_2014_Report.pdf

Paus-Hasebrink, I., Kulterer, J., \& Sinner, P. (2019). Social inequality, childhood and the media: A longitudinal study of mediatization and socialization. Springer Nature. https://doi.org/10.1007/978-3-030-02653-0

Radesky, J. S., Kistin, C. J., Zuckerman, B., Nitzberg, K., Gross, J., Kaplan-Sanoff, M., ... Silverstein, M. (2014). Patterns of mobile device use by caregivers and children during meals in fast food restaurants. Pediatrics, 133(4), e843-e849. https://doi.org/10.1542/peds.2013-3703

Radesky, J. S., Schumacher, J., \& Zuckerman, B. (2015). Mobile and interactive media use by young children: The good, the bad, and the unknown. Pediatrics, 135(1), 1-3. https://doi.org/10.1542/peds.2014-2251

Radesky, J. S., Weeks, H. M., Ball, R., Schaller, A., Yeo, S., Durnez, J., ... Barr, R. (2020). Young children's use of smartphones and tablets. Pediatrics, 146(1), e20193518. https://doi.org/10.1542/peds.2019-3518

Rideout, V. J. (2013). Zero to eight: Children's media use in America, 2013. Common Sense Media. Retrieved from https://www.commonsensemedia.org/research/zero-to-eight-childrens-media-use-in-america-2013

Rideout, V., \& Robb, M. B. (2020). The common sense census: Media use by kids age zero to eight, 2020. Common 
Sense Media. Retrieved from https://www.commonsensemedia.org/research/the-common-sense-census-media-useby-kids-age-zero-to-eight-2020

Roberts, J. A., \& David, M. E. (2016). My life has become a major distraction from my cell phone: Partner phubbing and relationship satisfaction among romantic partners. Computers in Human Behavior, 54, 134141. https://doi.org/10.1016/j.chb.2015.07.058

Schrock, A. R. (2016). Exploring the relationship between mobile Facebook and social capital: What is the "mobile difference" for parents of young children? Social Media + Society, 2(3), 111. https://doi.org/10.1177/2056305116662163

Steiner-Adair, C. \& Barker, T.H. (2013). The big disconnect: Protecting childhood and family relationships in the digital age. Harper Business.

Troseth, G. L., Russo, C. E., \& Strouse, G. A. (2016). What's next for research on young children's interactive media? Journal of Children and Media, 10(1), 54-62. https://doi.org/10.1080/17482798.2015.1123166

Turkle, S. (2011). Alone together: Why we expect more from technology and less from each other. New York, NY: Basic Books.

Wilken, R. (2011). Bonds and bridges: Mobile phone use and social capital debates. In R. Ling \& S.

W. Campbell (Eds.), Mobile communication: Bringing us together and tearing us apart (pp. 127-150). New Brunswick, NJ: Transaction Publishers.

Xie, X., Chen, W., Zhu, X., \& He, D. (2019). Parents' phubbing increases adolescents' mobile phone addiction: Roles of parent-child attachment, deviant peers, and gender. Children and Youth Services Review, 105(July), 104426. https://doi.org/10.1016/j.childyouth.2019.104426

Zhang, Y., \& Wildemuth, B. M. (2005). Qualitative Analysis of Content. Analysis, 1(2), 1-12.

\section{Copyrights}

Copyright for this article is retained by the author(s), with first publication rights granted to the journal.

This is an open-access article distributed under the terms and conditions of the Creative Commons Attribution license which permits unrestricted use, distribution, and reproduction in any medium, provided the original work is properly cited. 